\title{
Two Cases of Alleged Gang Rape Examined at Forensic Medicine Department of Sher-e-Bangla Medical College (SBMC) Barisal with Opinions Not "Enough to Prove the Allegation"
}

\author{
*SMT Haque ${ }^{1}$, AM Khan ${ }^{2}$, A Barek³ ${ }^{3}$ MH Chowdhury ${ }^{4}$, NT Khan ${ }^{5}$, M Akhteruzzaman ${ }^{6}$
}

\begin{abstract}
It is one of the most difficult tasks in forensic medicine is to examine alleged victims of sexual offence like rape that happened a few weeks back. There is a chance of miscarriage of justice. Two women were examined in the department of forensic medicine of SBMC. They gave the history of forceful sexual intercourse by several men at midnight while travelling in a bus. After their identification and obtaining informed written consent they were examined by 2 doctors, one is male and the other is female. With heavy responsibility on them the doctors had to proceed with the examination of the victims of alleged gang rape. Clinical examination, laboratory tests of collected specimens and X-ray examination were done. The opinions were that in case of the first victim, her age was around 18 years and in case of 2 nd victim, her age was around 17 years and in both victims, no signs of forceful sexual intercourse were present but signs of past sexual intercourse were present. If a consistency between the history given by the victim and signs detected by the examining doctors is established by the investigating legal officer then a positive result is expected from the court of trial but very often this does not happen.
\end{abstract}

Key Words: Rape, Foyensic Medicine

\section{Introduction}

Rape is a cognizable offence and so a police officer can arrest an accused of rape without a warrant from the court. It is a gang rape when the numbers of the rapists are several, may be two, three, four etc. They made sexual act on the victim forcefully one after another. Rape brings very vile effects with mental trauma by destructing the natural personal, familial and social reputation of both the victim and the rapist. There are statutory laws of definition of rape and punishment of the rapist if the case is proved in the court of law. For proving the allegation, the oral evidence of the victim and the report of the medical doctor on examination of the victim and subsequently his oral testimony in the court of law are very important. Many cases are lost because of the defects in both the evidences. Medical examination of the two victims of alleged gang rape are discussed in this article.

\footnotetext{
$1 *$ Dr. Syed Mohammad Tanjilul Haque, Associate Professor of Forensic Medicine \& Toxicology, Anwer Khan Modern Medical College, Dhaka

${ }^{2}$ Dr. Ahad Mahmud Khan, Research Investigator, Johns Hopkins University, Bangladesh Office, Dhaka.

${ }^{3}$ Prof. Dr. Abdul Barek, Honorary professor, Department of Forensic Medicine \& Toxicology, Anwer Khan Modern Medical College, Dhaka

${ }^{4}$ Prof. Dr. Md. Habibuzzaman Chowdhury, Professor and Head, Department of Forensic Medicine \& Toxicology, Anwer Khan Modern Medical College, Dhaka

${ }^{5}$ Dr. Nashid Tabassum Khan, Associate Professor \& Head of the Department of Forensic Medicine \& Toxicology, Z.H Sikder Women's Medical College, Dhaka.

${ }^{6}$ Dr. Md. Akhteruzzaman, Assistant Professor, Department of Forensic Medicine \& Toxicology, Sher-e-Bangla Medical College, Barisal
}

*Corresponding Author

Date of submission: 02.04.2017, Date of acceptance: 15.05.2017

AKMMC J 2017; 8(2) : 148-152 


\section{Case Report}

Two women alleging gang rape on them were examined in the department of forensic medicine of SBMC, Barisal. They were brought there by two policemen of Airport police station where the victims complained on the previous day. The police submitted a requisition letter, 3 attested photograph of each victim and physically identified the victims before the medical officers. The victims were examined by two doctors, one male and the other female. The victims were informed as to the nature of medical examination stating that they will be made naked, the whole body including the genitals will be examined by the female doctor and the report may go in their favour or against them. Each of them gave her consent by signing the consent form. They were examined in the examination room one after another. A third party female was present at the time of examination. The first woman gave the history of incident of forceful sexual intercourse on her by 5 young men one by one at midnight while they were travelling in a bus leaving from Barisal. The $2^{\text {nd }}$ victim stated that, she was forcefully raped by three of the said 5 men one after another. The victims knew the rapists. They complained to the police after 55 days of the incident because both the victim and the rapists tried to settle the problem amongst themselves without going to the police. After failure in the settlement, the women complained to the police. In their menstrual and sexual history the first women said that she was married but had no baby and the second woman was unmarried, their menstrual periods were normal and were not menstruating at the time of examination. They could not give any stained clothes worn at the time of sexual intercourse. Identification marks like moles and scar marks on the exposed part of the body were noted. Their height, weight, eruption of permanent teeth, appearance of axillary and pubic hairs, development of breast were noted. No injury indicating signs of restraint or struggle was found. Low and high vaginal swabs were taken for microscopic examination. All usual signs of past sexual intercourse like gapping of the labia majora, healed tear marks of the hymen, loss of rugae at the vaginal wall, allowing two examining fingers into the vagina easily. Capaciousness of the vagina was present. No signs of recent sexual intercourse like redress, swelling, edema, presence of spermatozoa in the vaginal swabs were found. Finally each victim was sent to the radiology and imaging department of SBMCH for radiological determination of medicolegal age. Then they were released.

After obtaining the X-ray report and laboratory test reports opinion of each victim was given in separate report form and those were sent to the investigating police officer. The related papers were obtained from the Head, Dept of Forensic Medicine SBMC, Barisal.

\section{Discussion}

Medico legal examination of the alleged rape victim is very difficult task in forensic medicine. Danger of true offence to go unpunished, injustice of wrong conviction, infliction of heavy penalties to the convicted person for such offences, personal, familial and social consequences of such vile offence heavily depend on the report of examining doctor ${ }^{1}$. When a normal deflorated woman is raped, signs of rape may not be detected. If she has taken bath after the act or washed the genital parts or a condom was used by the rapist or three or more days are passed away. If a virgin women is raped, her hymen may not be torn, if it was of loose, thick, elastic, fleshy, fringe, annular type. An unscrupulous woman having recent sex with her husband or any other man may accuse her enemy of rape on her. Rarely honesty and sincerity of the doctor who has examined the victim has been a great factor to give a right and genuine report as early as possible. Now a days news media publish such exciting cases of rape and create a huge public outcry.

As per law rape is defined as sexual intercourse by a man with any woman other than his wife below the age of 16 years with or without her consent, or with any woman other than his wife at or above the age of 16 years against her will, without her consent or even her consent when it has been obtained by some unlawful means like fear, force, fraud and also when the woman believes that this man is her another husband and the man knows that she has 
already has a lawful husband ${ }^{2,3}$. Consent of intoxicated, insane or mentally subnormal woman is also invalid. For the offence of rape punishment is awarded to the rapist.

To discuss such cases of gang rape, identification of the victims, informed written consent of each for medicolegal examination, examination by a female doctor, presence of third party woman during examination, menstrual and past sexual history of the victims, detailed history of the concerned incident of alleged rape, determination of the age of the victims, their demeanours, signs of struggle and restraint to avoid forceful sexual intercourse, changed genital findings, collection of vaginal swab and stained clothes used at the time of incident and testing these materials, interpretation of the medical findings and test reports and giving complete and right opinion need to be considered.

Two victims understudy, were identified by two escorting policemen before the examining doctors of SBMCH. Visual identification is based on the facial appearance and its complexion with other features of the face. This is the common way of identifciaotn. Attested photograph of each victim was attached with the requisition letter of the police officer. It was compared with face of the victim. The doctors noted one or two moles or scar marks over the exposed parts of the body to prove that they examined the victim having those moles and marks and not others. So, identification ${ }^{4,5}$ is important to establish the exact victim and not any hired woman was presented for winning the case.

Each victim gave informed written consent ${ }^{6,7}$ for such kind of special medicolegal examination. Ethically and legally a doctor cannot carry out such type of medical examination involving genitals without the informed written consent of the victim. The victim was explained about the nature and consequence of such intimate examination. The victim has the right to refuse such examination. The police and the doctor cannot force her for such examination and if it done against her consent, this will amount to an offence of the examiner.

General examination of the victim was done by a male doctor, but genital parts were examined by a female doctor. In the past, where female doctor was not available, a male doctor used to do complete examination of the victim in presence of a third party female attendant. It is to avoid shame and hesitation felt by the victim as well as to avoid any complaint of sex related ill behaviour of the male doctor towards the victim. At present, female doctor has be made available by the order of government authority. Still a third party female attendant is kept present in the examination room to avoid any complaint by a female victim and to remove her tension.

At the time of examination neither of the two victims were in their menstrual period. Menstrual blood certainly interferes with microscopic examination of the specimen and interpreting the result. If the victim is in her period possible examination is done and she is again examined when she is free from the period.

Of the two victims, one woman was already married and had sexual relationship with her husband though she had no pregnancy and the other victim was unmarried and claimed to be virgin before the above mentioned incident of gang rape.

In the victim No. 1, who was married and deflorated all genital signs of past sexual intercourse were present ${ }^{8,9}$. In the victim No.2, who was an unmarried woman, all genital signs of past sexual intercourse were also present. No signs of recent sexual intercourse were seen. Signs of struggle or restraint were also absent.

The incident took place about 55 days back. Signs of struggle or restraint such as small abrasion and bruises to prevent sexual intercourse, even there were any, might have healed up within one or two weeks time ${ }^{10}$. Both the women under study were mentally sound with normal demeanour. Any evasive or brazen attitude of the women might arouse suspicion that their allegation were without foundation. A real victim is distressed, agitated and angry over the act on her.

Vaginal specimens taken during medical examination did not show any spermatozoa. Usually spermatozoa may be recovered from living vagina within two or three days after the act if the vagina was not washed with water. Expecting spermatozoa 
in there cases are absurd, but could be present if the victim had again sexual act with a male within 2 to 3 days before the examination.

Swabs collected from the vagina may not show any spermatozoa if the man was already vasectomised or naturally azoospermic, Semen with or without spermatozoa can be detected by some tests like alkaline phosphatase test and p 30 glycoprotein test $^{11,12,13}$. Presence of spermatozoa or semen in the vagina indicates recent sexual intercourse.

The victim could not give any stained clothes worn at the time of incident. If stained clothes were available, these could be tested for semen or any blood of the rapists. At present DNA profiling can be done with the nucleated cells. DNA profile data obtained from the specimens may be compared with those of the suspected rapists confirming their offence and identification.

Age of the victim has a relation with the offence of rape as stated in the definition of rape. The age of the first victim medically determined was about 18 years and of the $2^{\text {nd }}$ victim about 17 years. So in this case, the trait age lost its significance as to the offence of rape.

\section{In Both Cases, the Opinions were Almost Similar:}

Case I: opinion was that (a) the age of the victim was about $18 \pm 1 / 2$ years and (b) no sign of forceful sexual intercourse was found during medical examination but signs of past sexual intercourse were present.

Case II: Opinion was that (a) the age of the victim was between 16 and 17 years (b) no sign of forceful sexual intercourse was found during medical examination but signs of past sexual intercourse were present.

\section{Points in Favour of Forceful Rape as Claimed by the Victims were:}

1. Their history of the incident.

2. Signs of past sexual intercourse found during medical examination.

\section{Points Against Forceful Rape were:}

1. A long delay of filing complaints to the police after the incident.

2. No signs of force, fear or fraud detected.

3. Signs of past sexual intercourse could be of any intercourse before or after the given incident.

4. Signs of sexual intercourse of the first victim could be due to sexual act with her husband.

5. The accused rapists were known to them and the intercourse could be of consenting nature.

6. Age of the victim were above 16 years.

So, it would be very difficult to prove the alleged offence in the court of law. Proving the case always lies with the complainants and the prosecuting party. Thus a true case, if it is supposed so, may be lost in the judgment.

After a sexual act with consent an unscrupulous woman can put a man in danger claiming that the act was done without her consent and will. An unscrupulous man can seduce a woman or promise to marry her and do sexual act with her and afterwards reject her. Then it will be medically difficult to give opinion in favour of rape or against it. Following rape an illegal pregnancy may result and in most such cases abortion is carried out. A few raped women may suffer from a chronic psychiatric illness with features of tension, feeling of guilt, humiliation, phobia, nightmares etc, which is known as rape trauma syndrome.

In a few instances, a raped victim may be murdered by rapists by pressure over neck, head injury, stabbing, destroying all evidences ${ }^{14,15,16}$. Even in such cases, the policeman can interrogate the suspected persons, may collect some evidences and can establish a link between the offence and the offenders.

Many cases of rape are not reported at all because of fear, pressure or injury to reputation. Thus it is a very difficult task on the part of the doctor to examine and report on an alleged case of rape especially that took place a few weeks ago. 


\section{Conclusion}

Most of the victims are brought to the examining doctor lately for medicolegal examination when signs of struggle, restraint and genital signs of sexual intercourse are lost. Then it becomes very difficult to find out the signs and diagnose that illegal sexual intercourse took place in the deflorated woman. History given by the victim as to the alleged sexual intercourse is important. The consistency of the history with the medical findings should convince the investigating legal officer to form a charge of rape against the rapist. Spermatozoa detected from the vaginal swab taken from an unmarried woman confirm sexual intercourse. Age 16 years is important. As below this age, sexual intercourse with or without her consent is rape. Using force, fear, fraud in sexual intercourse is also important. One incident of rape may produce mental trauma in the victim to destroy her future life. False allegation of rape must be excluded. By DNA examination, certainty of the sexual intercourse and identification of the rapist are possible.

\section{Conflict of interest: none.}

\section{References}

1. Knight B, Sexual offences, In: Simpson's Forensic Medicine, $10^{\text {th }}$ Edn, ELBS with Edward Arnold Kent, 1991: P 206-218

2. Ministry of law and justice, govt of the People's Republic of Bangladesh. Of Rape. In: The Penal Code, Dhaka, 1991, P-99

3. Bangladesh Gazette, extra. Government of the People's Republic of Bangladesh. Repression of woman and children Act, 1995. July 17. Section-2C, P-2410. \& Bangladesh Gazette, extra. Government of the People's Republic of Bangladesh. Repression of woman and children Act, 2000. February14. Section-9, P-636

4. Reddy KSN, Sexual offence, In: The Essentials of Forensic Medicine and Toxicology, 24th Edn 2005, Hyderabad, published by K Suguna Devi, P 335- 354.
5. Nandy A, Sexual offence \& Perversions, In: Nandy's Handbook of Forensic Medicine \& Toxicology, $1^{\text {st }}$ Edn, New Central Book Agency (P) Ltd. Hyderabad, 2013: 437-463

6. Modi JP. Sexual offences. In: Modi's Textbook of Medical Jurisprudence, $21^{\text {st }}$ Edn. C.A Franklin ed. NK Tripathi. Bombay. 1998. 369378.

7. Parikh CK. Rape: Medicolegal Aspects. In: Parikh's Textbook of Medical Jurisprudence and Toxicology, $3^{\text {rd }}$ edn. CBS. Bombay 1981. 475-80.

8. Vij K. Medicolegal examination in sexual offences. In: Textbook of Forensic Medicine and Toxicology, $6^{\text {th }}$ Edn. Reed Elsevier (P) Ltd, Haryana. 2014. 297-313.

9. Barek A, A study on Pattern of alleged Rape cases at SBMC, Barisal. Anwer Khan Modern Medical College Journal, Vol 1, No.1, 2010, P 15-18.

10. Reade DJ. Early Investigations of sexual Assaults, Police Surgeon. 1985, April. 42-44.

11. Davies A, Wilson E. The Persistence of seminal constituents in human vagina. Forensic Science. 1974; 3: 45-55.

12. Willott GM, Allard JE. Spermatozoa: Their persistence after seminal intercourse. Forensic Sci. Int. 1982, 19: 135-54.

13. Kind SS. The Acid Phosphatase Test. In: Carry AS ed. Methods of Forensic Science. Vol. III, London. Inter science. 19: 267-87

14. Knight B, Death associated with sexual offence, In: Forensic Pathology, $1^{\text {st }}$ Edn, Edward Arnold, London, 1991, P 385-93.

15. Sagar SM, Sharma RK, Dogra TD. Study of sexual offences in south Delhi. Journal of Forensic Medicine and Toxicology, July-Dec; 9(3): 1992. 8-11.

16. Paul D. Medical Examination in the living. In: Taylor's Principles and practice of Medical Jurisprudence. Mant AK ed. $13^{\text {th }}$ edn. Churchil Livingston. Edinburgh, London. 1984. 80-89. 